\title{
Retroperitoneal Paraganglioma - a rare cause of arterial hypertension
}

\author{
Paraganglioma retroperitoneal. Una causa poco frecuente de hipertensión arterial
}

\author{
Isabel Silva ${ }^{1}$, M. Joana Santos², Rosa Cardoso ${ }^{3}$, Sofia Carvalho ${ }^{3}$, Sónia Vilaça ${ }^{4}$, Manuela Vasconcelos ${ }^{1}$ \\ Internal Medicine Department - Hospital de Braga (Portugal). Endocrinology Department - Hospital de Braga (Portugal). Anatomic Pathology Department \\ - Hospital de Braga (Portugal). General Surgery Department - Hospital de Braga (Portugal)
}

\begin{abstract}
Paragangliomas are rare neuroendocrine tumours, most commonly found in adults. These differ from pheochromocytomas in that their location is extra-adrenal, and they are responsible for about $1 \%$ of arterial hypertension aetiologies. We report the case of a 30 -year-old female whose past medical history was unremarkable. However, her arterial hypertension led to further examination in search of secondary aetiologies, in which a retroperitoneal mass and an increase in levels of catecholamines were detected; findings that led to the final diagnosis of paraganglioma. A multidisciplinary team, whose approach was to use pharmacological alpha-adrenergic blocking agents and a surgical resection of the lesion, treated the patient. The patient is clinically well but will continue to be monitored as an outpatient, and genetic testing is being encouraged.
\end{abstract}

Keywords: paraganglioma, catecholamines, neuroendocrine system, arterial hypertension.

\section{Introduction}

Paragangliomas, as well as pheochromocytomas, are neuroendocrine tumours, which often secrete catecholamines. This hypersecretion causes symptoms that are often difficult to control ${ }^{1}$. Pheochromocytomas originate in the medulla of the adrenal glands and make up $80-85 \%$ of cases, whereas paragangliomas originate extra-adrenally and make up $15-20 \%$ of cases. Paragangliomas are rare tumours, and although their precise incidence rate is unknown, it is estimated that they occur in 1-2 in 100,000 people ${ }^{2}$ and it is believed that many cases go undiagnosed. Up to $25 \%$ of paragangliomas are hereditary². The sporadic form is usually diagnosed in patients between the fourth and fifth decades of life, while hereditary forms tend to present at a younger age (before the age of 40$)^{3}$. There is no difference in the frequency of incidence between genders. It can occur in any racial group but it is less common amongst black people. Paragangliomas may be derived from the parasympathetic or sympathetic ganglia. Parasympathetic ganglia-derived paragangliomas are located almost exclusively in the base of the neck and the skull, usually arise from the carotid body and jugulotympanic ganglia and are usually non-functional (do not produce catecholamines) ${ }^{4}$. In contrast, sympathetic ganglia-derived paragangliomas can arise anywhere along the sympathetic chain from the base of the skull down to the urinary bladder and prostate (with high intra-abdominal prevalence) and in most cases secrete catecholamines ${ }^{5}$. Paragangliomas are a rare, but important cause of hypertension, causing less than $1 \%$ of hypertension cases ${ }^{2}$. They can also cause other symptoms associated with a hypermetabolic state and vasoconstriction. Diagnosis is based on the analysis of secreted biochemical products and the evaluation of imaging findings. The only curative treatment is surgery, however, this requires rigorous and long-term monitoring, both due to the risk of recurrence and because malignancy is not defined by histological criteria.

\section{Clinical case}

The patient is a 30-year-old caucasian female in whom a hypertensive peak $(180 / 110 \mathrm{mmHg})$ was detected in a routine health check-up. She had an unremarkable medical history and suffered from migraines without aura for which she had a Neurology consult where she was referred for an Internal Medicine consultation due to her persistently high blood pressure (systolic values between $160-180 \mathrm{mmHg}$ and diastolic values between $100-110 \mathrm{mmHg}$ ). The patient was taking an oral contraceptive and propranolol and is a non-smoker. She has a family history of hypertension (in her mother). In the Internal Medicine consultation she was encouraged to record her blood pressure levels regularly. Her physical exam was unremarkable, with the exception of postural blood pressure reduction. The weight of the patient is $53.5 \mathrm{~kg}$. A study/screening was led to determine whether she had secondary hypertension. There were normal electrocardiogram (ECG) results, normal ambulatory blood pressure monitoring (ABPM) results, normal systolic and diastolic BP in the patient's records, and initial analytical study with no notable changes. Slight dyslipidemia was detected, with total cholesterol levels of $217 \mathrm{mg} / \mathrm{dL}$, HDL $67 \mathrm{mg} / \mathrm{dL}$ and LDL 132mg/ $\mathrm{dL}$. There were normal results in the following blood workup: thyroid function, adrenocorticotropin (ACTH), cortisol, aldosterone and renin. Urinalysis was also normal. An upper abdominal and renovesical ultrasound showed a homogeneous nodular image behind the brain region of the pancreas and adjacent to the vena cava, measuring $33 \mathrm{~mm}$ and with well-defined contours. The possibility of it being a leiomyoma was discussed, although a differential diagnosis was made with retroperitoneal tumours, for which an abdominal-pelvic CT scan (CAT SCAN) was requested. An analytical survey in- 
Table 1. Analytical values found in the first assay.

\begin{tabular}{|c|c|c|c|c|c|c|}
\hline & \multicolumn{3}{|c|}{ Catecholamines } & \multicolumn{2}{|c|}{ Metanephrines } & \multirow{2}{*}{$\begin{array}{l}\text { Vanillylmandelic } \\
\text { acid }\end{array}$} \\
\hline & Dopamine & Adrenaline & Noradrenaline & Metanephrine & Normetanephrine & \\
\hline $\begin{array}{c}\text { Urinary } \\
\text { (24-hour urine } \\
\text { sample) }\end{array}$ & $\begin{array}{c}284.98 \mathrm{ug} / 24 \mathrm{~h} \\
(64.93-400)\end{array}$ & $\begin{array}{l}3.35 \mathrm{ug} / 24 \mathrm{~h} \\
(0.01-19.96)\end{array}$ & $\begin{array}{c}326.21 \mathrm{ug} / 24 \mathrm{~h} \\
(15-80)\end{array}$ & $\begin{array}{c}66.65 \mathrm{ug} / 24 \mathrm{~h} \\
(74-297)\end{array}$ & $\begin{array}{c}400.88 \mathrm{ug} / 24 \mathrm{~h} \\
(105-354)\end{array}$ & $\begin{array}{c}10.08 \mathrm{mg} / 24 \mathrm{~h} \\
(<13.60)\end{array}$ \\
\hline Plasma & $\begin{array}{c}70.24 \mathrm{pg} / \mathrm{mL} \\
(<87)\end{array}$ & $\begin{array}{c}33.56 \mathrm{pg} / \mathrm{mL} \\
(<90)\end{array}$ & $\begin{array}{c}1115.64 \mathrm{pg} / \mathrm{mL} \\
(110-700)\end{array}$ & $\begin{array}{c}0.06 \mathrm{nmol} / \mathrm{L} \\
(<0.46)\end{array}$ & $\begin{array}{c}1.58 \mathrm{nmol} / \mathrm{L} \\
(<0.98)\end{array}$ & \\
\hline
\end{tabular}

Table 2. Analytical values found one month after the surgery.

\begin{tabular}{|c|c|c|c|c|c|}
\hline & \multicolumn{3}{|c|}{ Catecholamines } & \multicolumn{2}{c|}{ Metanephrines } \\
\cline { 2 - 5 } & Dopamine & Adrenaline & Noradrenaline & Metanephrine & Normetanephrine \\
\hline Urinary & $280.84 \mathrm{ug} / 24 \mathrm{~h}$ & $2.18 \mathrm{ug} / 24 \mathrm{~h}$ & $34.74 \mathrm{ug} / 24 \mathrm{~h}$ & $62.76 \mathrm{ug} / 24 \mathrm{~h}$ & $105.84 \mathrm{ug} / 24 \mathrm{~h}$ \\
$\begin{array}{c}\text { (24-hour urine } \\
\text { sample) }\end{array}$ & $(64.93-400)$ & $(0.01-19.96)$ & $(15-80)$ & $(74-297)$ & $(105-354)$ \\
\hline
\end{tabular}

tended to measure urinary and plasma catecholamines and metanephrines and vanillylmandelic acid was also requested. The patient later referred to a relevant family history of a paragnaglioma in an older sister. The abdominal-pelvic CT scan showed a hypodense nodular lesion adjacent to the liver, behind the vena cava and to the right of the celiac artery at the level of its emergence with a significant, relatively homogenous absorption of iodine-based contrast media. Its dimensions were estimated to be $39 \times 24 \mathrm{~mm}$ and its limits and contours were well defined (figure 1). Its characteristics led to the main diagnostic hypothesis of paraganglioma, and the hypothesis of it being a lesion originating from the wall of the vena cava was deemed less likely.

The case was discussed taking into consideration imaging findings, and an abdominal Magnetic Resonance Imaging
(MRI) scan was still deemed necessary; the results of which supported the most likely diagnosis, the hypothesis that it was a paraganglioma. We did not observe signs of a haemorrhage, necrosis or intralesional calcifications and it did not appear to have any aggressive features, signs of involvement from adjacent organs or evidence to suggest vascular invasion. The patient came back later accompanied by a healthy, asymptomatic, brother and by a 31-year-old sister with a history of paraganglioma within the bladder wall. It was diagnosed in a routine examination when the patient's sister was 21 years old and required three surgeries in the space of one year. She was monitored in Urology consults but had already been discharged in the meantime.

The results of the more specific analytical study are expressed on table 1. Normal values are referred within

Figure 1. Abdominal CT scan showing the lesion (coronal plane and axial plane).

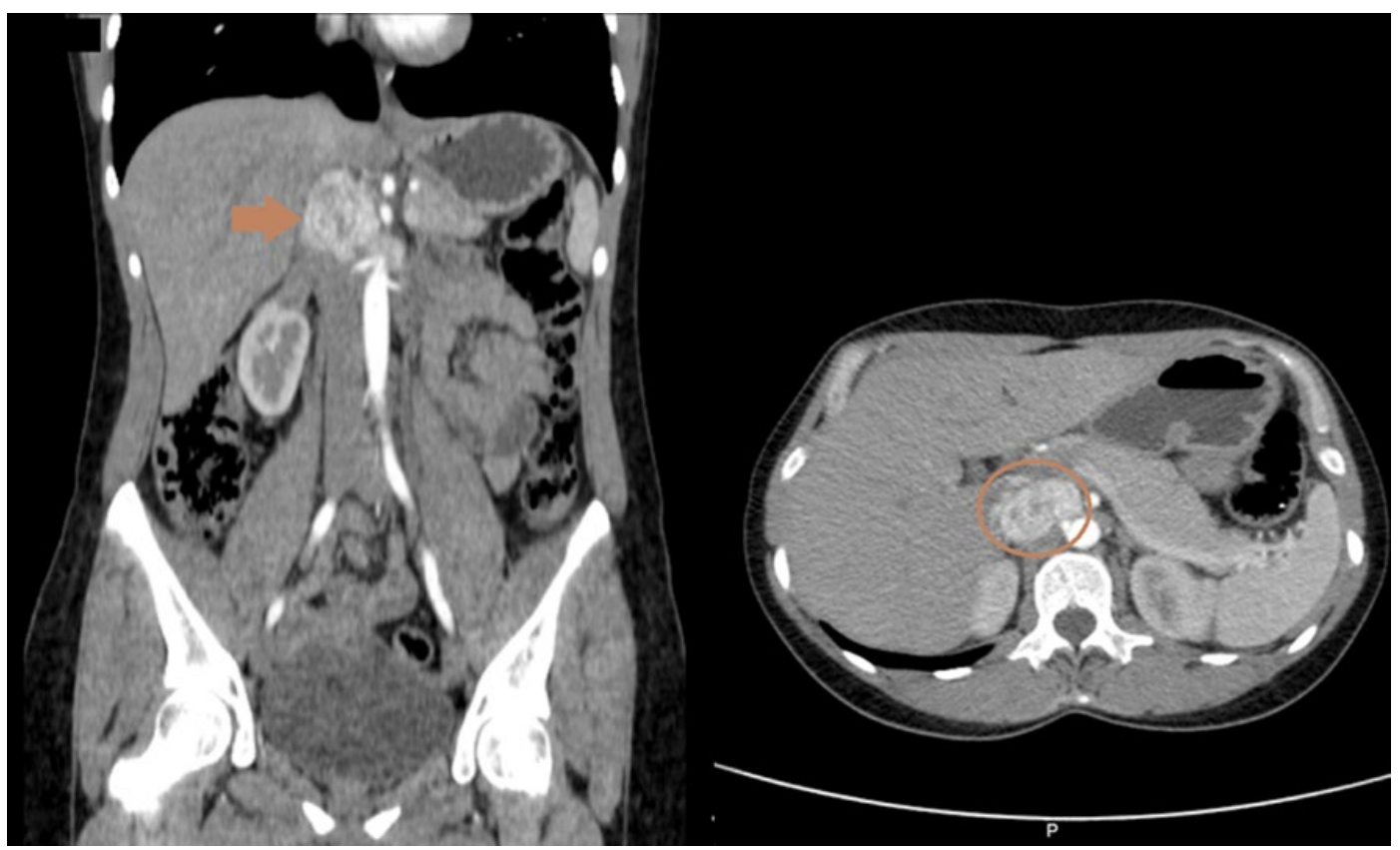


Figure 2. Perioperative image showing paraganglioma.

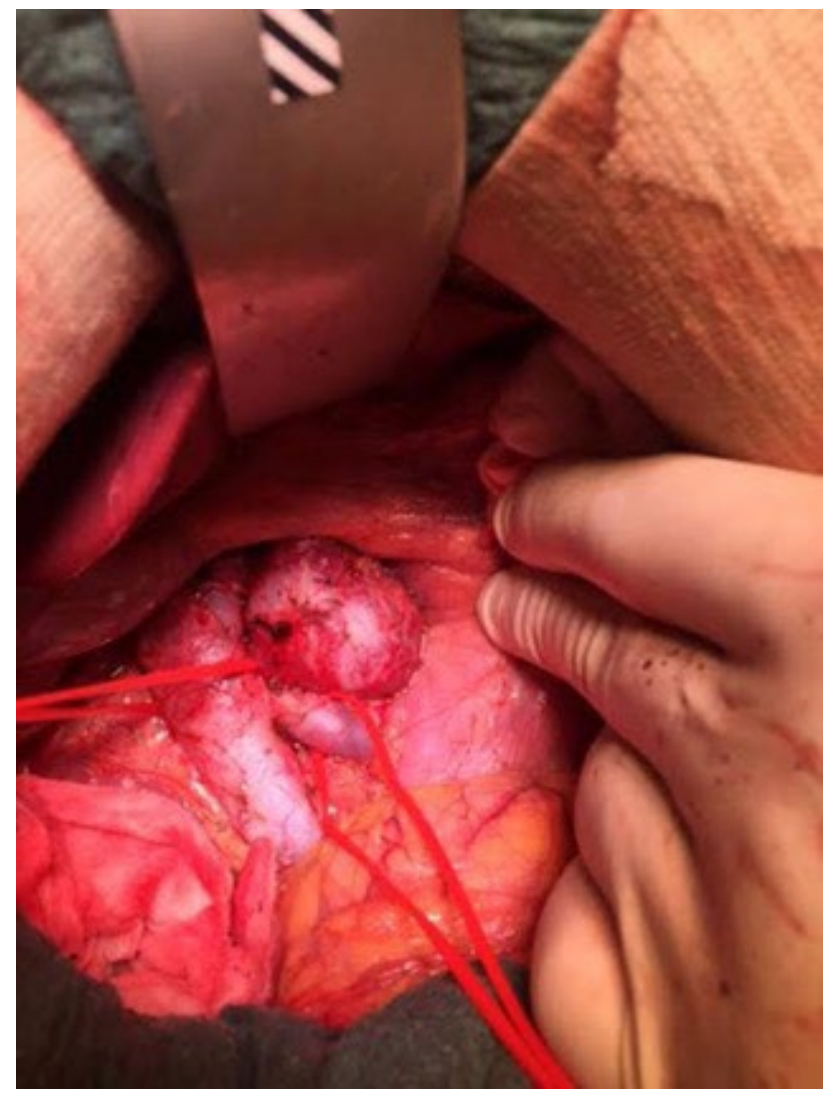

parentheses. Significant increased in noradrenaline and normetanephrine values were detected.

Due to the likely diagnosis of retroperitoneal paraganglioma, the patient was assigned to Endocrinology and General Surgery. Pre-operatively, the patient was treated with the Phenoxybenzamine (an alpha-receptor antagonist) at a dosage of $10 \mathrm{mg}$ twice a day. It was used to control symptoms beforehand and reduce the risk of intraoperative complications associated with tumour manipulation and the risk of catecholamines being released. Elective surgery by laparotomy (figure 2) was performed, where the entire mass was removed along with the resection of the interaortocaval lymph and adenopathy of the hepatic chain, which macroscopically presented reactive aspects. The surgical procedure took place without complications.

The anatomopathological study showed a nodular formation measuring $3.5 \mathrm{~cm}$ with a smooth, brownish outside surface covered in a thin capsule. No images of vascular invasion or invasion of the capsule were identified. We concluded that it was a paraganglioma with tumour-free surgical margins and an absence of metastatic involvement in the ganglia examined. The tumour is composed of two cell types: chief cells and sustentacular cells. Chief cells are positive for chromogranin and synaptophysin and sustentacular cells surround nests of chief cells and are positive for S100 protein. The histopathology of the paraganglioma revealed the typical "zellballen" pattern which is characterized by small groups of chief cells separated by septa and capillaries (figure 3). The patient is clinically stable, asymptomatic, and has controlled levels of blood pressure into normal ranges, so she stopped the anti-hypertensive. The noradrenaline and normetanephrine urinary values were normal one month after surgery (table 2).

She is still being monitored in appointments with Internal Medicine, Endocrinology and General Surgery, as long-term monitoring is essential. She is also being encouraged to have genetic tests done due to her young age and family history of a sister with bladder paraganglioma. The patient is still awaiting genetic consultation.

\section{Discussion}

The authors decided to present this case because it is a rare situation and to draw attention to the importance of making full etiologic study of arterial hypertension, namely in younger people.

Paragangliomas are rare, highly vascular neoplasms that may be solitary or multiple, sporadic or hereditary, benign or malignant. About 95\% of patients with pheocromocytomas/ paragangliomas present arterial hypertension (sustained or paroxysmal) and other symptoms related to "catecholaminergic" effects, and a hypermetabolic state are also common, such as tachycardia, anxiety, weight loss, ischaemia, constipation and even insulin resistance ${ }^{2,6}$.

Most tumours that secrete catecholamines are sporadic. However, about 25\% of cases are part of a hereditary disease $^{2}$. The hereditary forms often present as bilateral and multifocal neoplasms and at an earlier age than the sporadic forms. Susceptibility to develop either pheochromocytomas or paragangliomas was associated with germ mutations in some genes, for example in cases of type 2 multiple endocrine neoplasia (MEN2), type one neurofibromatosis (NF1), Von Hippel Lindau syndrome (VHL), Carney-Stratakis syndrome and genes encoding subunits $B, C$ and $D$ of the mitochondrial enzyme succinate dehydrogenase $(\mathrm{SDH})^{7,8}$. It remains a controversial question as to whether it is necessary for all patients with pheochromocytomas/paragangliomas to be genetically tested. In general, genetic tests are recommend for patients with bilateral tumours, positive family history or diagnosis before the age of $50^{2}$.

The presumptive preoperative diagnosis of a paraganglioma can be done through biochemical tests and the evaluation of imaging results. However, the definitive diagnosis requires an assessment of the histopathology of tissue which is usually only conducted after the surgical resection of the tumour. Carrying out a biopsy is not recommended due to the risk of causing severe hypertension from a catecholamine crisis.

The analytical study was done by measuring plasma metanephrines (metanephrine and normetanephrine), catecholamine metabolites that give a clear indication of diagnosis ${ }^{9}$, for which normal values practically exclude pheochromocytoma/paraganglioma ${ }^{3}$. With regards to imaging, CT and MRI scans are 


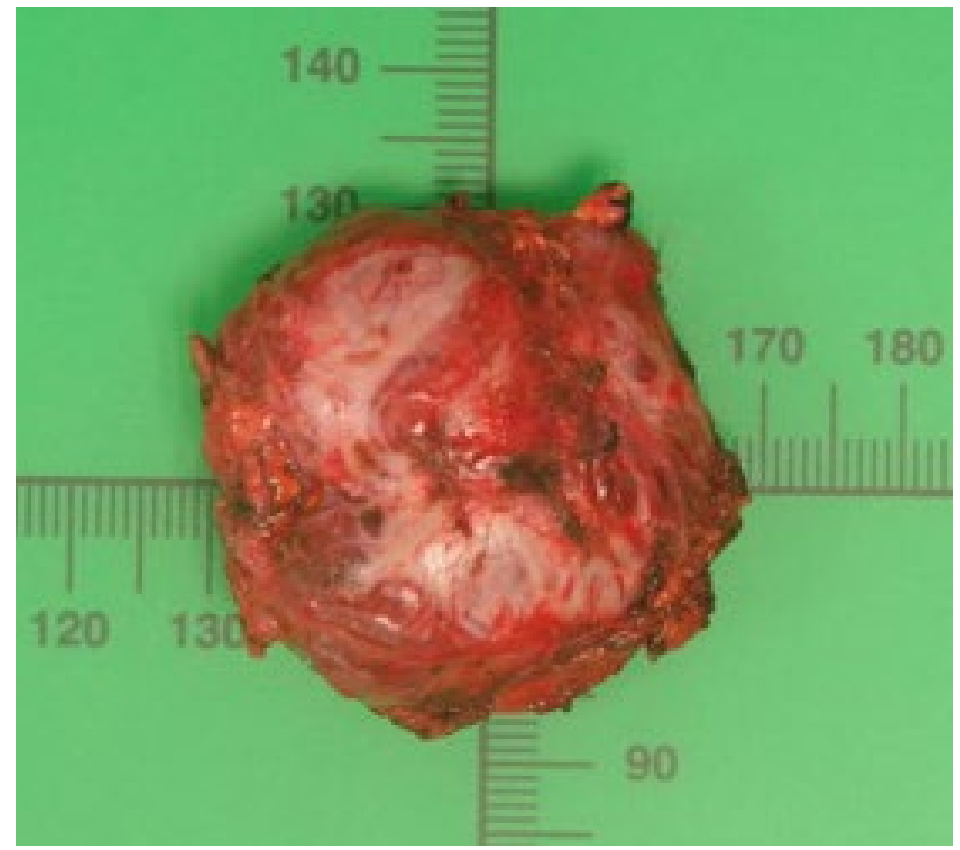

the tests of choice, as both have high sensitivity (98-100\%) in identifying adrenal tumours. However, MRI scans are better at identifying paragangliomas ${ }^{10}$ and they have the advantage of not exposing the patient to radiation or contrast media.

Tumour removal surgery remains the only curative treatment for pheochromocytomas and paragangliomas ${ }^{3,10}$. Ideally, the surgery should be done laparoscopically due to the lower morbidity-mortality rate associated with it, but certain conditions require that the approach be laparotomic such as the tumour being bigger than $5 \mathrm{~cm}$ in size and being located extra-adrenally $y^{3,7}$, as was the case with this patient.

Patients with benign, solitary lesions have a good prognosis with normalised analytical parameters and blood pressure after the entire lesion is surgically removed. However, blood pressure may remain high if residual vascular hypertrophy or renal dysfunction sequelae occur. Recurrence rates are variable and can go from zero to about $15 \%$ of cases ${ }^{3}$. Early diagnosis of a hereditary syndrome would allow strategies to be put in place for the monitoring, diagnosis and treatment in the early stages of a paraganglioma, improving the global prognosis.

\section{Take home messages}

- Secretory paraglionomas are rare neuroendocrine tumors responsible for $1 \%$ of hypertensive cases.

- Paraganglionomas more common below diaphragm and typically secret noradrenaline and normetanephrines.

- Paraganglionomas are hereditary in 1 in 4 cases. Family history and screening should form part of work up of these cases.

- Surgery is curative for paraglionomas but a long term surveillance is necessary.

\section{References}

1. DeLellis RA, Lloyd RV, Heitz PU, Eng C, editors. WHO Classification of Tumours: Pathology and Genetics of Tumours of the Endocrine Organs. Lyon: IARC press; 2004.

2. Oliveira M, Silva G, Machado R, Lima O, Ramires R, Marcelo F. Paraganglioma retro-peritoneal - um diagnóstico raro mas importante. Acta Urológica. 2009; 26(4): 47-53.

3. Gubert APN, Nery FM, Anghinoni M, Sena RHR. Paraganglioma Retroperitoneal relato de caso. Rev. Med. Res. 2013; 15(2): 125-131.

4. Erickson D, Kudva YC, Ebersold MJ, et al. Benign paragangliomas: clinical presentation and treatment outcomes in 236 patients. J Clin Endocrinol Metab. 2001; 86: 5210.

5. Lee JA, Duh QY. Sporadic paraganglioma. Wordl J Surg 2008; 32: 683.

6. Manger WM, Gifford RW. Clinical and experimental pheochromocytoma, seconded. Cambridge: Blackwell Sciences; 1996.

7. Adler JT, Meyer-Rochow GY, Chen H, Benn DE, Robinson BG, Sippel RS, et al. Pheochromocytoma: current approaches and future directions. Oncologist. 2008; 13(7): 779-793.

8. Parenti G, Zampetti B, Rapizzi E, Ercolino T, Giachè V, Mannelli M. Updated and new perspectives on diagnosis, prognosis and therapy of malignant Pheochromocytoma/ paraganglioma. J Oncol. 2012; 2012: ID872713.

9. Lenders JWM, Eisenhofer G, Mannelli M, Pacak K. Phaeochromocytoma. Lancet 2005; 366(9486): 655-75.

10. Nobre F, Amodeo C, Consolim-Colombo F, Correia M, Gus M. Hipertensão arterial sistémica secundária. Rev Bras Hipertens. 2010; 17 (1): 44-51. 